\title{
Upregulated miR-193a-3p as an oncogene in esophageal squamous cell carcinoma regulating cellular proliferation, migration and apoptosis
}

\author{
YUNFENG YI, JIANMING CHEN, CHANGJIE JIAO, JING ZHONG, \\ ZHIMING SONG, XIAOPING YU, XIUJUAN LU and BAOLI LIN
}

Department of Thoracic Surgery, Dongnan Affiliated Hospital of Xiamen University, Zhangzhou, Fujian 363000, P.R. China

Received April 25, 2015; Accepted July 7, 2016

DOI: $10.3892 / 01.2016 .5229$

\begin{abstract}
MicroRNAs (miRs) are small endogenous non-coding RNAs that play a vital role in carcinogenesis. miR-193a-3p has been described in multiple cancers. However, the function of miR-193a-3p in esophageal squamous cell carcinoma (ESCC) is still unclear. To explore the role of miR-193a-3p in ESCC, reverse transcription-quantitative polymerase chain reaction was used to evaluate the expression of miR-193a-3p in 48 paired ESCC and adjacent normal tissues. In addition, the impact of miR-193a-3p on cell proliferation, migration and apoptosis were analyzed by 3-(4,5-dimethylthiazol-2-yl)-2,5-diphenyltetrazolium bromide assay, wound scratch assay and flow cytometry, respectively. The results revealed that miR-193a-3p was upregulated in ESCC, compared with adjacent normal tissues. Downregulation of miR-193a-3p expression using a synthesized inhibitor suppressed cell proliferation and migration, and induced cell apoptosis, indicating that miR-193a-3p could be characterized as an oncogene in ESCC. In summary, the present study demonstrated that miR-193a-3p was upregulated in ESCC, where it plays a significant role by affecting cellular proliferation, migration and apoptosis.
\end{abstract}

\section{Introduction}

Esophageal carcinoma is the fifth and eighth most common cause of mortality worldwide in men and women, respectively (1). In Eastern Asia, esophageal squamous cell carcinoma (ESCC) is the predominant type of esophageal carcinoma, with $>100$ cases/100,000 population reported annually (2). ESCC is also the major histological type in Chinese populations, resulting in 150,000 mortalities annually (3). Despite the availability of

Correspondence to: Professor Baoli Lin, Department of Thoracic Surgery, Dongnan Affiliated Hospital of Xiamen University, 269 Zhanghuazhong Road, Zhangzhou, Fujian 363000, P.R. China E-mail: linbaoli001@126.com

Key words: ESCC, miR-193a-3p, upregulated, oncogene multiple treatments for ESCC, surgical resection remains the primary choice for non-metastatic cases (4). However, even upon curative surgery, the 5-year survival rate for ESCC patients is only $26.2-49.4 \%$, due to local or distant recurrences (5). Therefore, it is critical to identify novel molecular mechanisms to elucidate ESCC oncogenesis and metastasis.

MicroRNAs (miRs) are small endogenous non-coding RNAs that play vital roles in various biological processes $(6,7)$. Mature microRNAs usually bind to 3'-untranslated regions (3'-UTRs) of target genes, leading to messenger RNA degradation or repression of translation, thus downregulating the expression of target genes at post-transcriptional levels $(6,8)$. Since the first microRNA (microRNA-lin-4) was identified in 1993, an increasing number of microRNAs have been reported to be involved in numerous physiological and pathological processes, including carcinogenesis $(9,10)$. Several microRNAs, including miR-21, miR-34a and miR-155, have been observed to be associated with carcinogenesis by targeting oncogenes or anti-oncogenes (11-13).

In the present study, the expression of miR-193a-3p was examined in ESCC specimens, and the function of miR-193a-3p in ESCC cells was investigated via cell migration, proliferation and apoptosis assays. The results revealed that miR-193a-3p was upregulated in ESCC tissues and functioned as an oncogene in ESCC by affecting cellular migration, proliferation and apoptosis.

\section{Materials and methods}

ESCC tissue samples collection. All ESCC tissues and adjacent normal tissues used in the present study were collected from Dongnan Affiliated Hospital of Xiamen University (Zhangzhou, China) between February, 2013 and December, 2014. Written informed consent was obtained from all patients. The collection and use of these samples was approved by the Ethics Committee of Dongnan Affiliated Hospital of Xiamen University. Fresh ESCC and adjacent normal tissues were immersed in RNAlater (Qiagen GmbH, Hilden, Germany) in $30 \mathrm{~min}$ following resection, and subsequently stored at $-80^{\circ} \mathrm{C}$.

RNA isolation and reverse transcription-quantitative polymerase chain reaction $(R T-q P C R)$. According to the 
manufacturer's protocol, total RNA was extracted with TRIzol reagent (Invitrogen; Thermo Fisher Scientific, Inc., Waltham, MA, USA) and purified with RNeasy Maxi kit (Qiagen $\mathrm{GmbH})$. Total RNA (1 $\mu \mathrm{g}$ of each sample) was used for RT using miScript RT kit (Qiagen $\mathrm{GmbH}$ ) to obtain the complementary DNA (cDNA) templates. qPCR reaction of miR-193a-3p was performed in an ABI PRISM ${ }^{\circledR}$ 7000 Real-Time PCR System (Applied Biosystems; Thermo Fisher Scientific, Inc.) using miScript SYBR Green PCR kit (Qiagen $\mathrm{GmbH}$ ). U6 was used as an endogenous control. The $20 \mu \mathrm{l}$ reaction mixture contained 2X QuantiTect SYBR Green PCR Master mix $(10 \mu 1), 10 X$ miScript Universal Primer $(2 \mu \mathrm{l})$, specific microRNA primer $(0.4 \mu \mathrm{l})$, cDNA template $(1 \mu \mathrm{l})$ and RNase-free water. The forward primer of miR-193a-3p was 5'-AACTGGCCTACAAAGTCCCAGT-3' and the reverse primer was provided in the miScript SYBR Green PCR kit. The forward primer and reverse primers of U6 were 5'-CTC GCTTCGGCAGCACA-3' and 5'-ACGCTTCACGAATTT GCGT-3', respectively. Amplification conditions were set as: $95^{\circ} \mathrm{C}$ for $2 \mathrm{~min}$, followed by 40 cycles of $94^{\circ} \mathrm{C}$ for $15 \mathrm{sec}, 58^{\circ} \mathrm{C}$ for $30 \mathrm{sec}$ and $72^{\circ} \mathrm{C}$ for $30 \mathrm{sec}$.

Cell culture and transfection. The human ESCC cell lines Eca109 and TE-1 used in the present study were purchased from the Shanghai Institute of Biochemistry and Cell Biology (Shanghai, China), and were cultured in RPMI 1640 (Invitrogen; Thermo Fisher Scientific, Inc.) supplemented with $10 \%$ fetal bovine serum (Invitrogen; Thermo Fisher Scientific, Inc.), $100 \mathrm{U} / \mathrm{ml}$ penicillin and $100 \mathrm{~g} / \mathrm{ml}$ streptomycin at $37^{\circ} \mathrm{C}$ in a humidified incubator containing $5 \% \mathrm{CO}_{2}$. For the downregulation of miR-193a-3p expression, a synthesized miR-193a-3p inhibitor (Shanghai GenePharma Co., Ltd., Shanghai, China) was transfected into the cells using Lipofectamine 2000 (Invitrogen; Thermo Fisher Scientific, Inc.) according to the manufacturer's protocol. The transfection efficiency and changes in miR-193a-3p expression were determined by fluorescence microscopy and RT-qPCR, respectively.

Migration assay. The migratory ability of ESCC cells (Eca109 and TE-1) in vitro was assessed by wound scratch assay. Approximately 150,000 cells were seeded in a 12-well dish and were transfected with miR-193a-3p inhibitor (60 pmol) or negative control (60 pmol) with Lipofectamine $200024 \mathrm{~h}$ later. After $5 \mathrm{~h}$ of transfection, a vertical wound was created with the tip of a sterile $10-\mu 1$ pipette, and markers were assigned to enable the observation of cells in the correct location. The cells were then rinsed three times with phosphate-buffered saline (PBS) and incubated at $37^{\circ} \mathrm{C}$. Images of the wound scratches were captured with a digital camera system at 0 and $24 \mathrm{~h}$ after the wounds were made at the same location. Wound widths $(\mu \mathrm{m})$ were measured with a standard caliper, and the experiments were performed in triplicate and analyzed by at least two observers.

3-(4,5-dimethylthiazol-2-yl)-2,5-diphenyltetrazolium bromide (MTT) assay. Cell proliferation of ESCC lines (Eca109 and TE-1) was assessed with an MTT assay kit (Sigma-Aldrich, St. Louis, MO, USA). Approximately 5,000 cells were seeded into 96-well plates and transfected with 5 pmol of miR-193a-3p inhibitor or negative control. Next, $20 \mu \mathrm{l}$ of MTT $(5 \mathrm{mg} / \mathrm{ml}$; Sigma-Aldrich) was added to the culture medium of each well at $0,24,48$ and $72 \mathrm{~h}$ post-transfection. After incubation for $4 \mathrm{~h}$, the MTT medium was removed, and $150 \mu \mathrm{l}$ of dimethyl sulfoxide was added. After shaking for $15 \mathrm{~min}$ at room temperature, the optical density (OD) of each sample was assessed with an enzyme-linked immunosorbent assay instrument (model 680; Bio-Rad Rad Laboratories, Inc., Hercules, CA, USA) at a wavelength of 490/630 $\mathrm{nm}$.

Flow cytometry. For apoptosis assay, ESCC cells (Eca109 and TE-1) were cultured in 6-well plates at $37^{\circ} \mathrm{C}$ and transfected with miR-193a-3p inhibitor or negative control at a confluence of $\sim 65 \%$. After $48 \mathrm{~h}$ of transfection, cells were harvested and washed twice with cold PBS, resuspended in $10 \mu 11 \mathrm{X}$ binding buffer (Invitrogen; Thermo Fisher Scientific, Inc.). Subsequently, $5 \mu \mathrm{l}$ of Annexin V-fluorescein isothiocyanate (Invitrogen; Thermo Fisher Scientific, Inc.) and $10 \mu \mathrm{l}$ of propidium iodide were added to each sample. The fluorescence of the stained cells was then analyzed by flow cytometry (Beckman Coulter, Inc., Brea, CA, USA) using an excitation wavelength of $488 \mathrm{~nm}$ within $30 \mathrm{~min}$ of staining, according to the manufacturer's protocol.

Statistical analysis. Statistical analysis was conducted with SPSS 17.0 statistical software package (SPSS, Inc., Chicago, IL, USA). Statistical significance was determined with paired $t$-test and Student's $t$ test. $\mathrm{P}<0.05$ was considered to indicate a statistically significant difference.

\section{Results}

Upregulation of miR-193a-3p in 36 paired ESCC tissues and adjacent normal tissues by RT-qPCR. RT-qPCR was used to determine the expression of miR-193a-3p in 36 paired ESCC tissues and adjacent normal tissues. The relative expression of miR-193a-3p is represented in Fig. 1A. As shown in Fig. 1B, the miR-193a-3p expression in ESCC tissues was significantly higher than that in adjacent normal tissues $(\mathrm{P}=0.0153)$.

Transfection and inhibition efficiency. To determine the function of miR-193a-3p in ESCC, miR-193a-3p inhibitor and negative control were transfected into the ESCC cell lines Eca109 and TE-1. Images of the cells transfected with fluorescein amidite-labeled negative control were obtained at $6 \mathrm{~h}$ post-transfection, and revealed that the transfection efficiency was $\sim 85$ and $80 \%$ in Eca109 and TE-1 cells, respectively (Fig. 2A). Compared with the negative control, the relative expression of miR-193a-3p in Eca109 and TE-1 cells transfected with miR-193a-3p inhibitor was 5.5 and $7.3 \%$, respectively (Fig. 2B). These results suggested that the miR-193a-3p inhibitor used in the present study was able to effectively downregulate the expression of miR-193a-3p.

Downregulation of miR-193a-3p suppresses ESCC cell migration in vitro. Wound scratch assay was performed to determine the effects of miR-193a-3p on ESCC cell migration in vitro. Compared with the negative control group, the wound widths of Eca109 and TE-1 cells transfected with miR-193a-3p inhibitor were significantly wider $(\mathrm{P}=0.0322$ and 0.0306 , respectively; Fig. 3), which indicated that downregulation of miR-193a-3p inhibited the migration of ESCC cells (Fig. 3). 
A

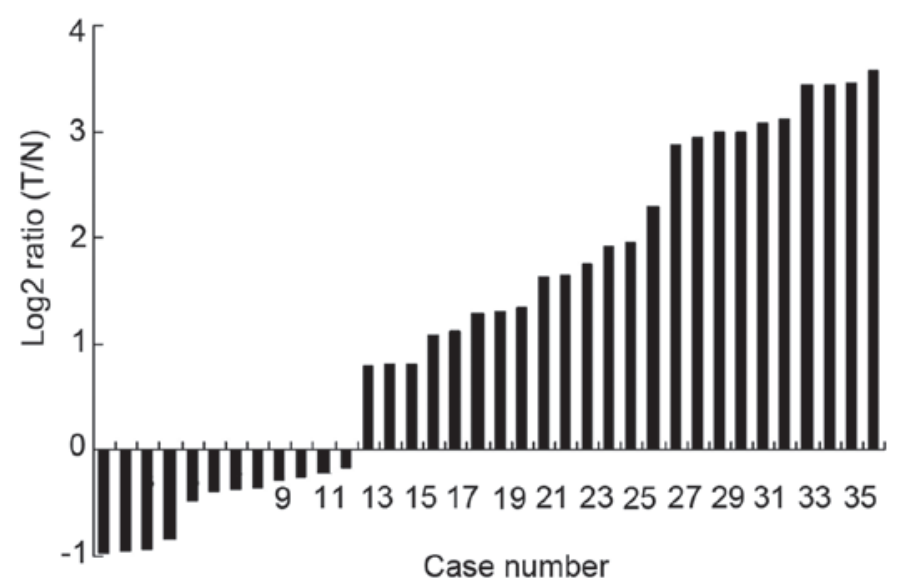

B

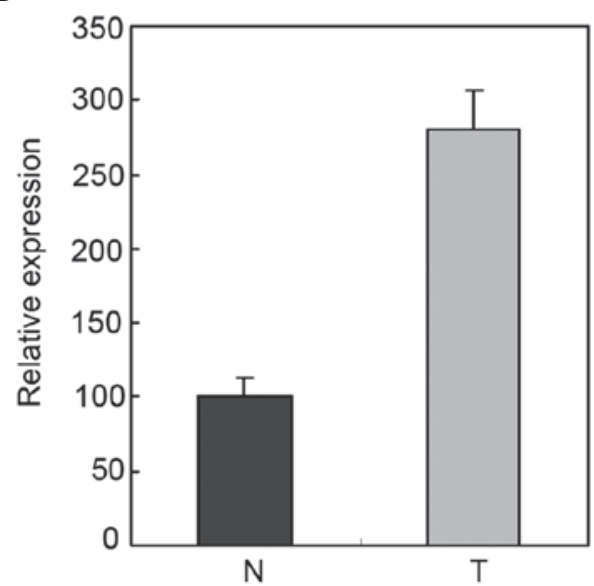

Figure 1. Expression of miR-193a-3p in 36 paired ESCC tissues and normal esophageal tissues. (A) $\log _{2}$ ratios of miR-193a-3p expression in 36 paired ESCC tissues and normal esophageal tissues. (B) Relative expression of miR-193a-3p in ESCC tissues and normal esophageal tissues ( $\mathrm{P}=0.0153)$. Data are presented as the mean \pm standard error. ESCC, esophageal squamous cell carcinoma; miR, microRNA; T, ESCC tissues; N, normal tissues.

A

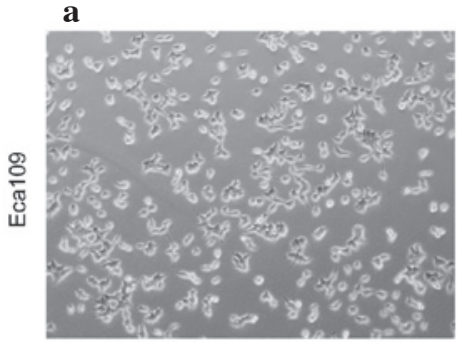

c

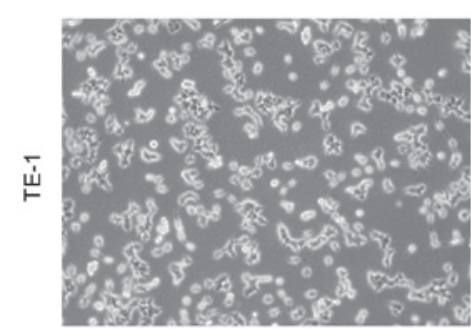

b

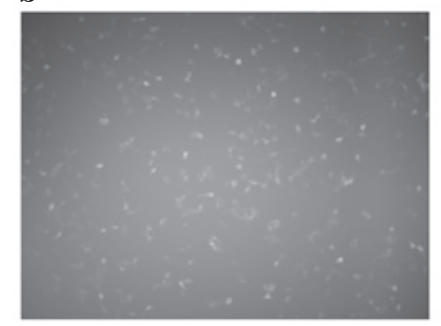

d

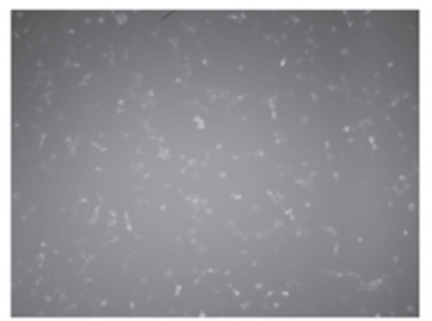

B

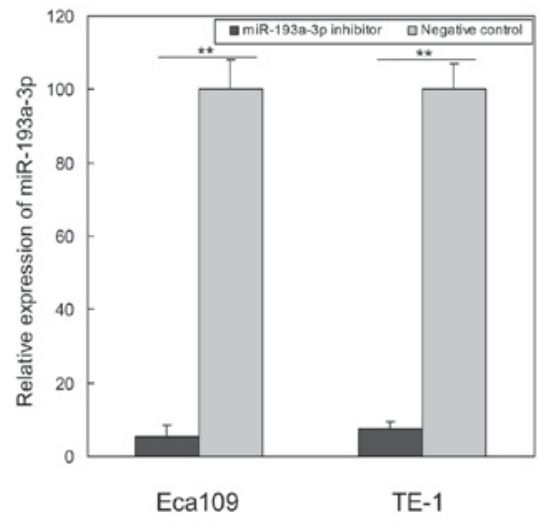

Figure 2. Analysis of transfection efficiency and miR-193a-3p expression levels by fluorescence microscopy and reverse transcription-quantitative polymerase chain reaction. (A) The transfection efficiency was 85 and $80 \%$ in Eca109 and TE-1 cells, respectively (magnification, x200). (a) Eca109 cells transfected with Fam-labeled negative control. (b) Eca109 cells exhibiting green fluorescence 6 h after transfection with Fam-labeled negative control. (c) TE-1 cells transfected with Fam-labeled negative control. (d) TE-1 cells exhibiting green fluorescence $6 \mathrm{~h}$ after transfection with Fam-labeled negative control. (B) Fold-changes in miR-193a-3p expression in Eca109 and TE-1 cells treated with miR-193a-3p inhibitor or negative control were analyzed 24 h after transfection. Data are presented as the mean \pm standard deviation. ${ }^{* *} \mathrm{P}<0.01$ vs. the negative control. All experiments were performed in triplicate. miR, microRNA; Fam, fluorescein amidite.

Reduction of miR-193a-3p inhibits cell proliferation. The impact of miR-193a-3p on cell proliferation in ESCC was analyzed by MTT assay. The OD values of miR-193a-3p inhibitor group and negative control group were measured at $0,24,48$ and $72 \mathrm{~h}$ post-transfection. The results indicated that the proliferation of Eca109 cells decreased by $6.45 \%(\mathrm{P}=0.0318), 10.63 \%(\mathrm{P}=0.0131)$ and $14.19 \%(\mathrm{P}=0.0019)$, while the proliferation of TE-1 cells decreased by $6.78 \%(\mathrm{P}=0.0356), 11.51 \%(\mathrm{P}=0.0152)$ and $14.72 \%$ $(\mathrm{P}=0.0025)$, at 24,48 and $72 \mathrm{~h}$ post-transfection, respectively (Fig. 4). This indicated that downregulation of miR-193a-3p suppressed the proliferation of ESCC cells in vitro.

Inhibition of miR-193a-3p promotes ESCC cell apoptosis. To determine the function of miR-193a-3p on ESCC cell apoptosis, flow cytometry was performed to detect the apoptosis rates upon transfection. As represented in Fig. 5, the apoptosis rates of Eca109 cells transfected with miR-193a-3p inhibitor and negative control were 7.2 and $2.7 \%(\mathrm{P}=0.0121)$, respectively, following transfection for $48 \mathrm{~h}$. The apoptosis rates of TE-1 cells were 6.6 and $2.8 \%(\mathrm{P}=0.0154)$ upon transfection with miR-193a-3p inhibitor and negative control, respectively. These results demonstrated that inhibition of miR-193a-3p induced ESCC cell apoptosis.

\section{Discussion}

Carcinogenesis involves the activation of a number of oncogenes and the inactivation of a number of anti-oncogenes (14). 
A
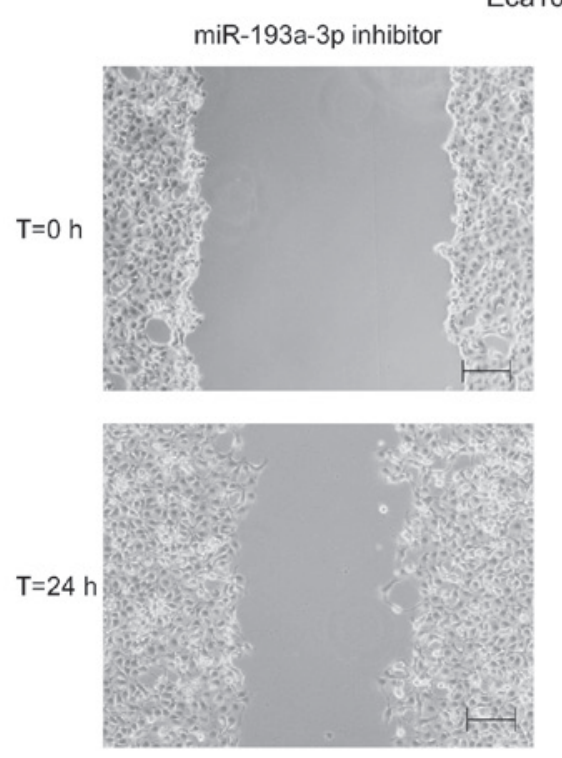

C
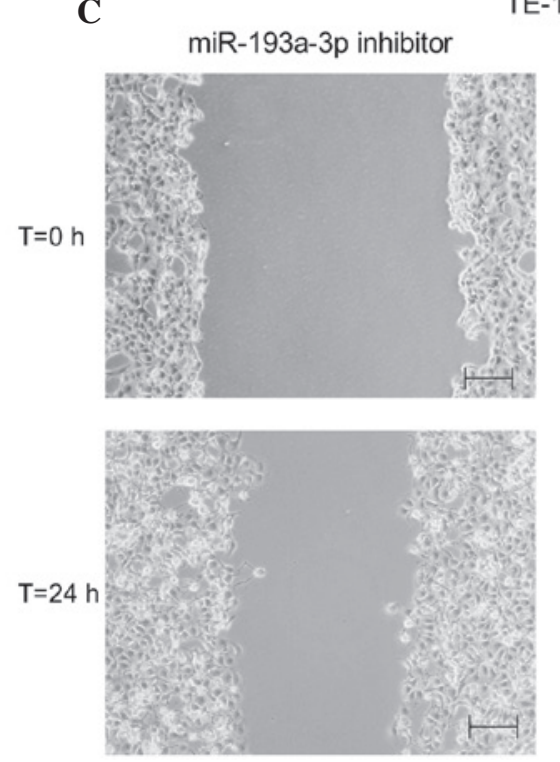

Eca109
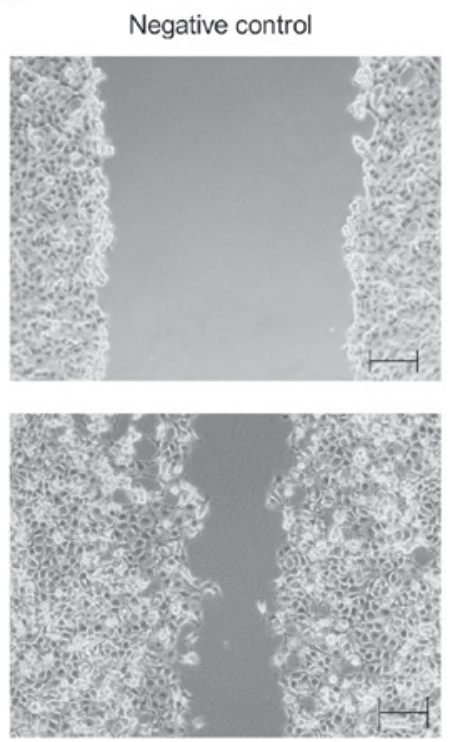

B

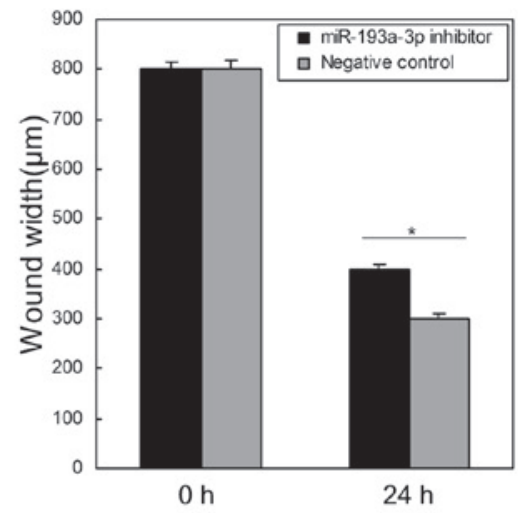

D
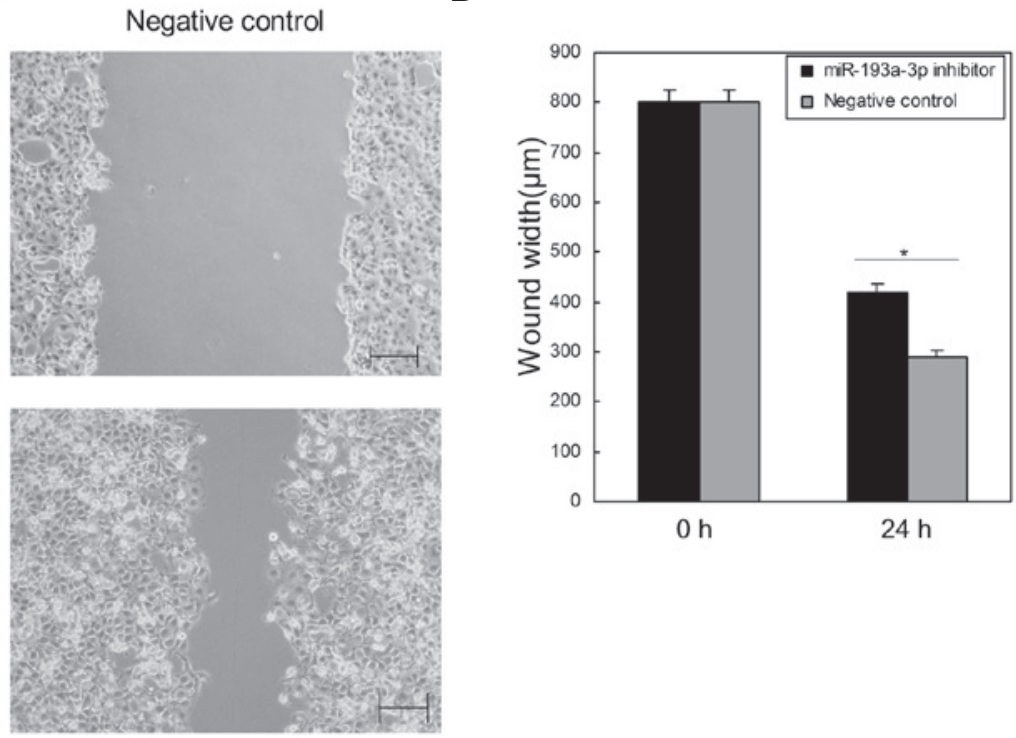

$0 \mathrm{~h}$

$24 \mathrm{~h}$

Figure 3. Wound scratch assay for Eca109 and TE-1 cells $24 \mathrm{~h}$ after transfection. (A) Images of Eca109 cells transfected with miR-193a-3p inhibitor or negative control at 0 and $24 \mathrm{~h}$ after the wounds were made at the same point (scale bar=200 $\mu \mathrm{m}$ ). (B) Comparison of wound widths $(\mu \mathrm{m})$ in Eca109 cells using a standard caliper. (C) Images of TE-1 cells transfected with miR-193a-3p inhibitor or negative control at 0 and $24 \mathrm{~h}$ after the wounds were made at the same point (scale bar $=200 \mu \mathrm{m})$. (D) Comparison of wound widths $(\mu \mathrm{m})$ in TE-1 cells using a standard caliper. Data are presented as the mean \pm standard error. ${ }^{*} \mathrm{P}<0.05 \mathrm{vs}$. the negative control. The experiments were performed in triplicate. T, time; miR, microRNA.

A

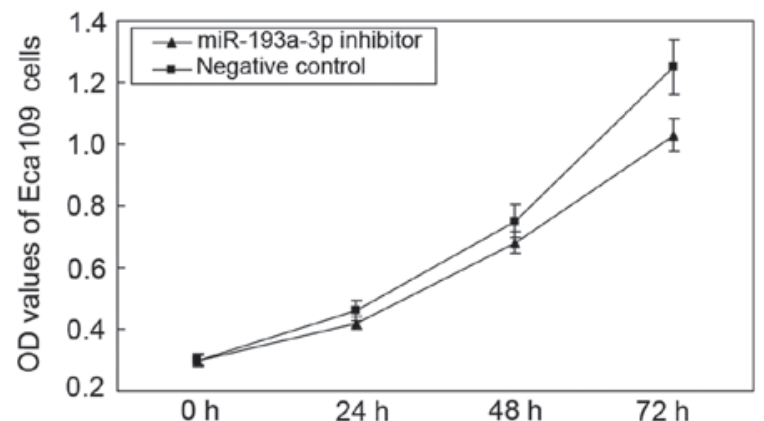

B

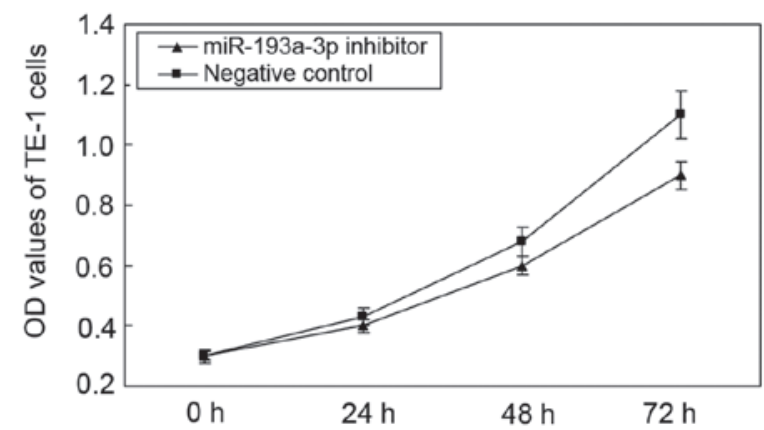

Figure 4. 3-(4,5-dimethylthiazol-2-yl)-2,5-diphenyltetrazolium bromide assay for cell proliferation assessment of Eca109 and TE-1 cells transfected with miR-193a-3p inhibitor or negative control. (A) Cell proliferation of Eca109 cells. (B) Cell proliferation of TE-1 cells. Data are presented as the mean \pm standard deviation of three measurements. miR, microRNA; OD, optical density. 
A

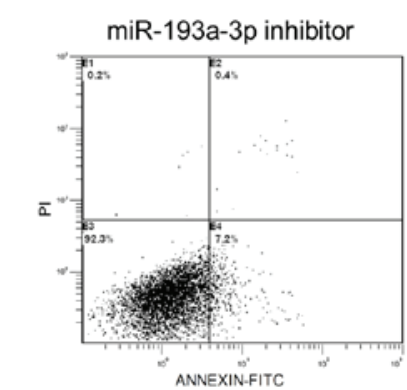

B

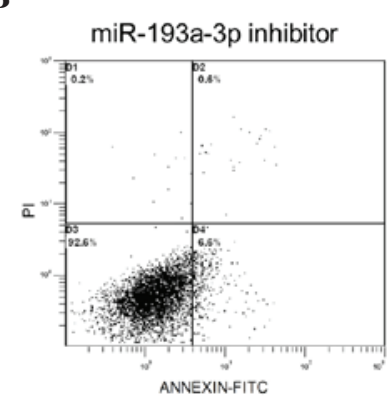

Eca109

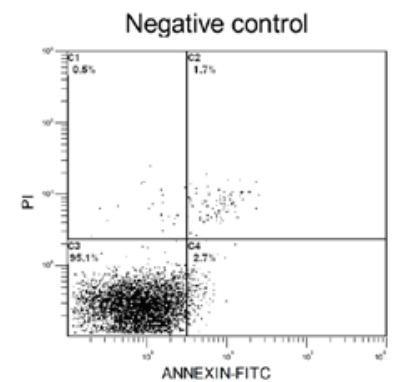

TE-1

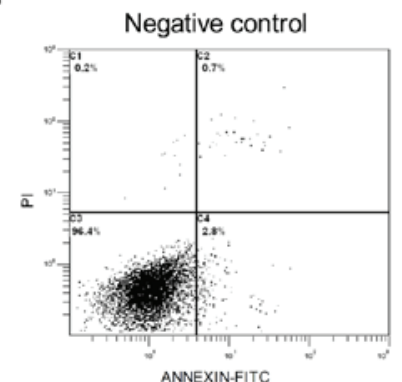

C

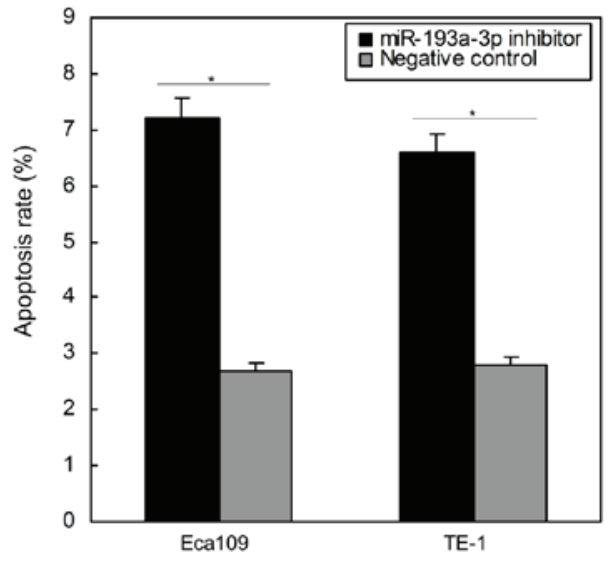

Figure 5. Flow cytometry analysis of cell apoptosis in Eca109 and TE-1 cells transfected with miR-193a-3p inhibitor or negative control. (A) Eca109 cells transfected with miR-193a-3p inhibitor (left panel) or negative control (right panel). (B) TE-1 cells transfected with miR-193a-3p inhibitor (left panel) or negative control (right panel). (C) Comparison of apoptosis rates in cells transfected with miR-193a-3p inhibitor or negative control. Data are presented as the mean \pm standard deviation of three measurements. ${ }^{*} \mathrm{P}<0.05$ vs. the negative control. miR, microRNA; FITC, fluorescein isothiocyanate; PI, propidium iodide.

In the complicated regulatory network of oncogenes and anti-oncogenes, microRNAs plays a vital role by controlling the expression of target genes at post-transcriptional levels (15). By regulating the levels of oncogenes or anti-oncogenes, a microRNA can act as an anti-oncogene or as an oncogene (8). Although only accounting for a small fraction of the expressed genome, microRNAs play crucial roles in diverse cellular processes, including cell proliferation, cellular differentiation, cell death, metabolism, apoptosis, motility, invasion and morphogenesis $(6,10,16-20)$. A number of microRNAs were observed to be upregulated in ESCC, including miR-21 (21-23), miR-205 (24), miR-10b (25), miR-23a (26), miR-26a (26), miR-27b (26), miR-96 (26), miR-128b (26), miR-129 (26), miR-93 (23), miR-192 (23) and miR-194 (23). In addition, downregulation of miR-375 (21), miR-203 (23), miR-205 (23), miR-27b (23), miR-125b (23) and miR-100 (23) expression has been detected in ESCC. Furthermore, numerous microRNAs were noticed to play the role of oncogene or anti-oncogene in ESCC, including miR-21, which facilitates ESCC growth by targeting phosphatase and tensin homolog and programmed cell death $4(22,27)$; miR-296, which contributes to ESCC growth by targeting cyclin D1 and p27 (28); miR-210, which targets fibroblast growth factor receptor-like 1, thus exerting a negative effect on cell cycle and proliferation (29); miR-145, miR-133a and miR-133b, which converge to target fascin 1, thus reducing cell growth and invasion (30); and miR-593, which may contribute to carcinogenesis through polo-like kinase 1 (31).

miR-193a-3p can function as a tumor suppressor, since it inhibits cell-cycle progression and proliferation in breast cancer through targeting epidermal growth factor receptor-driven cell-cycle network proteins (32) and induces apoptosis in both U-251 and HeLa cells (33). In addition, miR-193a-3p suppresses the metastasis of human non-small-cell lung cancer $(34,35)$.
However, the expression and role of miR-193a-3p in ESCC remains unclear.

To determine the expression and role of miR-193a-3p in ESCC, RT-qPCR was used in the present study to quantify the miR-193a-3p level in 36 cases of ESCC tissues and paired normal tissues. The present study demonstrated that miR-193a-3p expression was significantly upregulated in ESCC tissues, compared with its expression levels in paired normal esophageal tissues. The effects of miR-193a-3p on ESCC cell migration, proliferation and apoptosis were then analyzed by transfection of ESCC cell lines with a synthetic miR-193a-3p inhibitor. Transfection of miR-193a-3p inhibitor into the ESCC cell lines Eca109 and TE-1 inhibited cellular proliferation and migration and induced apoptosis, compared with the negative control group. These findings suggested that miR-193a-3p may act as a oncogene in ESCC by inhibiting cellular proliferation and migration and by promoting cellular apoptosis. Further studies on miR-193a-3p target genes are required to clarify the mechanism of action of miR-193a-3p in ESCC.

The role of miR-193a-3p in different cancers appears to be controversial, as it was identified as a tumor suppressor in certain cancers (32-35) and as an oncogene in ESCC, according to the results of the present study. Regardless of experimental error, this contradiction may be explained as 'imperfect' complementary interactions between microRNAs and their target genes. Contrary to small interfering RNA, the interactions between microRNAs and the 3'-UTRs of their target genes are not always perfectly complementary (particularly in mammals), which leads to relative rather than complete specificity between microRNAs and their target genes (36). Accurate interactions between microRNAs and their target genes may be further dictated by cell types and the 
microenvironment, thus contributing to the divergent regulatory roles of certain microRNAs $(6,37)$.

In conclusion, the present study revealed that miR-193a-3p was upregulated in ESCC and played a vital oncogenic role in ESCC by affecting cellular migration, proliferation and apoptosis. Further studies are required to define its mechanism of action in ESCC.

\section{References}

1. Jemal A, Bray F, Center MM, Ferlay J, Ward E and Forman D: Global cancer statistics. CA Cancer J Clin 61: 69-90, 2011.

2. Pennathur A, Gibson MK, Jobe BA and Luketich JD: Oesophageal carcinoma. Lancet 381: 400-412, 2013.

3. Zhao P, Dai M, Chen W and Li N: Cancer trends in China. Jpn J Clin Oncol 40: 281-285, 2010.

4. Han LH, Jia YB, Song QX, Wang JB, Wang NN and Cheng YF: Prognostic significance of preoperative lymphocyte-monocyte ratio in patients with resectable esophageal squamous cell carcinoma. Asian Pac J Cancer Prev 16: 2245-2250, 2015.

5. Liu J, Xie X, Zhou C, Peng S, Rao D and Fu J: Which factors are associated with actual 5-year survival of oesophageal squamous cell carcinoma? Eur J Cardiothorac Surg 41: e7-e11, 2012.

6. Jiang L, Liu X, Chen Z, Jin Y, Heidbreder CE, Kolokythas A, Wang A, Dai Y and Zhou X: MicroRNA-7 targets IGF1R (insulin-like growth factor 1 receptor) in tongue squamous cell carcinoma cells. Biochem J 432: 199-205, 2010.

7. Soeda S, Ohyashiki JH, Ohtsuki K, Umezu T, Setoguchi Y and Ohyashiki K: Clinical relevance of plasma miR-106b levels in patients with chronic obstructive pulmonary disease. Int J Mol Med 31: 533-539, 2013.

8. Xiong Y, Zhang L, Holloway AK, Wu X, Su L and Kebebew E: MiR-886-3p regulates cell proliferation and migration and is dysregulated in familial non-medullary thyroid cancer. PLoS One 6: e24717, 2011.

9. Ha TY: MicroRNAs in Human Diseases: From cancer to Cardiovascular Disease. Immune Netw 11: 135-154, 2011.

10. Zhai Q, Zhou L, Zhao C, Wan J, Yu Z, Guo X, Qin J, Chen J and Lu R: Identification of miR-508-3p and miR-509-3p that are associated with cell invasion and migration and involved in the apoptosis of renal cell carcinoma. Biochem Biophys Res Commun 419: 621-626, 2012

11. Shibuya H, Iinuma H, Shimada R, Horiuchi A and Watanabe T: Clinicopathological and prognostic value of microRNA-21 and microRNA-155 in colorectal cancer. Oncology 79: 313-320, 2010

12. Akao Y, Noguchi S, Iio A, Kojima K, Takagi $T$ and Naoe T: Dysregulation of microRNA-34a expression causes drug-resistance to 5-FU in human colon cancer DLD-1 cells . Cancer Lett 300: 197-204, 2011.

13. Tili E, Michaille JJ, Wernicke D, Alder H, Costinean S, Volinia S and Croce CM: Mutator activity induced by microRNA-155 (miR-155) links inflammation and cancer. Proc Natl Acad Sci USA 108: 4908-4913, 2011.

14. Yu Z, Ni L, Chen D, Zhang Q, Su Z, Wang Y, Yu W, Wu X, Ye J, Yang $\mathrm{S}$ et al: Identification of miR-7 as an oncogene in renal cell carcinoma. J Mol Histol 44: 669-677, 2013.

15. Jing Q, Huang S, Guth S, Zarubin T, Motoyama A, Chen J, Di Padova F, Lin SC, Gram H and Han J: Involvement of microRNA in AU-rich element-mediated mRNA instability. Cell 120: 623-634, 2005.

16. Bhattacharyya S, Balakathiresan NS, Dalgard C, Gutti U, Armistead D, Jozwik C, Srivastava M, Pollard HB and Biswas R: Elevated miR-155 promotes inflammation in cystic fibrosis by driving hyperexpression of interleukin-8. J Biol Chem 286: 11604-11615, 2011

17. Lucotti S, Rainaldi G, Evangelista M and Rizzo M: Fludarabine treatment favors the retention of $\mathrm{miR}-485-3 \mathrm{p}$ by prostate cancer cells: Implications for survival. Mol Cancer 12: 52, 2013.

18. Sarver AL, French AJ, Borralho PM, Thayanithy V, Oberg AL, Silverstein KA, Morlan BW, Riska SM, Boardman LA, Cunningham JM, et al: Human colon cancer profiles show differential microRNA expression depending on mismatch repair status and are characteristic of undifferentiated proliferative states. BMC Cancer 9: 401, 2009.
19. Bentwich I, Avniel A, Karov Y, Aharonov R, Gilad S, Barad O, Barzilai A, Einat P, Einav U, Meiri E, et al: Identification of hundreds of conserved and nonconserved human microRNAs. Nat Genet 37: 766-770, 2005.

20. Liu X, Yu J, Jiang L, Wang A, Shi F, Ye H and Zhou X: MicroRNA-222 regulates cell invasion by targeting matrix metalloproteinase 1 (MMP1) and manganese superoxide dismutase 2 (SOD2) in tongue squamous cell carcinoma cell lines. Cancer Genomics Proteomics 6: 131-139, 2009.

21. Mathe EA, Nguyen GH, Bowman ED, Zhao Y, Budhu A, Schetter AJ, Braun R, Reimers M, Kumamoto K, Hughes D, et al: MicroRNA expression in squamous cell carcinoma and adenocarcinoma of the esophagus: Associations with survival. Clin Cancer Res 15: 6192-6200, 2009.

22. Hiyoshi Y, Kamohara H, Karashima R, Sato N, Imamura Y, Nagai Y, Yoshida N, Toyama E, Hayashi N, Watanabe M and Baba H: MicroRNA-21 regulates the proliferation and invasion in esophageal squamous cell carcinoma. Clin Cancer Res 15: 1915-1922, 2009.

23. Feber A, Xi L, Luketich JD, Pennathur A, Landreneau RJ, Wu M, Swanson SJ, Godfrey TE and Litle VR: MicroRNA expression profiles of esophageal cancer. J Thorac Cardiovasc Surg 135: 255-260; discussion 260, 2008.

24. Matsushima K, Isomoto H, Kohno S and Nakao K: MicroRNAs and esophageal squamous cell carcinoma. Digestion 82: 138-144, 2010.

25. Tian Y, Luo A, Cai Y, Su Q, Ding F, Chen H and Liu Z: MicroRNA-10b promotes migration and invasion through KLF4 in human esophageal cancer cell lines. J Biol Chem 285: 7986-7994, 2010.

26. Ogawa R, Ishiguro H, Kuwabara Y, Kimura M, Mitsui A, Katada T, Harata K, Tanaka T and Fujii Y: Expression profiling of micro-RNAs in human esophageal squamous cell carcinoma using RT-PCR. Med Mol Morphol 42: 102-109, 2009.

27. Ma WJ, Lv GD, Tuersun A, Liu Q, Liu H, Zheng ST, Huang CG, Feng JG, Wang X, Lin RY, et al: Role of microRNA-21 and effect on PTEN in Kazakh's esophageal squamous cell carcinoma. Mol Biol Rep 38: 3253-3260, 2011.

28. Hong L, Han Y, Zhang H, Li M, Gong T, Sun L, Wu K, Zhao Q and Fan D: The prognostic and chemotherapeutic value of miR-296 in esophageal squamous cell carcinoma. Ann Surg 251: 1056-1063, 2010 .

29. Tsuchiya S, Fujiwara T, Sato F, Shimada Y, Tanaka E, Sakai Y, Shimizu K and Tsujimoto G: MicroRNA-210 regulates cancer cell proliferation through targeting fibroblast growth factor receptor-like 1 (FGFRL1). J Biol Chem 286: 420-428, 2010.

30. Kano M, Seki N, Kikkawa N, Fujimura L, Hoshino I, Akutsu Y, Chiyomaru T, Enokida H, Nakagawa $M$ and Matsubara $\mathrm{H}$ : miR-145, miR-133a and miR-133b: Tumor-suppressive miRNAs target FSCN1 in esophageal squamous cell carcinoma. Int J Cancer 127: 2804-2814, 2010.

31. Ito T, Sato F, Kan T, Cheng Y, David S, Agarwal R, Paun BC, Jin Z, Olaru AV, Hamilton JP, et al: Polo-like kinase 1 regulates cell proliferation and is targeted by miR-593* in esophageal cancer. Int J Cancer 129: 2134-2146, 2011.

32. Uhlmann S, Mannsperger H, Zhang JD, Horvat EÁ, Schmidt C, Küblbeck M, Henjes F, Ward A, Tschulena U, Zweig K, et al: Global microRNA level regulation of EGFR-driven cell-cycle protein network in breast cancer. Mol Syst Biol 8: 570, 2012.

33. Kwon JE, Kim BY, Kwak SY, Bae IH and Han YH: Ionizing radiation-inducible microRNA miR-193a-3p induces apoptosis by directly targeting Mcl-1. Apoptosis 18: 896-909, 2013.

34. Yu T, Li J, Yan M, Liu L, Lin H, Zhao F, Sun L, Zhang Y, Cui Y, Zhang F, et al: MicroRNA-193a-3p and -5p suppress the metastasis of human non-small-cell lung cancer by downregulating the ERBB4/PIK3R3/mTOR/S6K2 signaling pathway. Oncogene 34: 413-423, 2015.

35. Deng W, Yan M, Yu T, Ge H, Lin H, Li J, Liu Y, Geng Q, Zhu M, Liu L, et al: Quantitative Proteomic analysis of the metastasis-inhibitory mechanism of miR-193a-3p in non-small cell lung cancer. Cell Physiol Biochem 35: 1677-1688, 2015.

36. Kim VN: MicroRNA biogenesis: Coordinated cropping and dicing. Nat Rev Mol Cell Biol 6: 376-385, 2005.

37. Kharaziha P, Ceder S, Li Q and Panaretakis T: Tumor cell-derived exosomes: A message in a bottle. Biochim Biophys Acta 1826: 103-111, 2012. 